\title{
Climate vulnerability assessment in semi-arid and arid region of Rajasthan, India: An enquiry into the disadvantaged districts
}

\author{
NAVEEN P. SINGH ${ }^{1}$, SURENDRA SINGH ${ }^{1}$, BHAWNA ANAND ${ }^{1}$ and S. K. BAL ${ }^{2}$ \\ ${ }^{1} I C A R$-National Institute of Agricultural Economics \& Policy Research, New Delhi 110012 \\ ${ }^{2} I C A R$-Central Research Institute for Dryland Agriculture, Hyderabad - 500059 \\ E-mail:*naveenpsingh@gmail.com
}

\begin{abstract}
This paper assesses the district level climate vulnerability in the state of Rajasthan using largescale data on climate and socio-economic variables.More than thirty indicators segregated into four components of exposure, sensitivity, adaptive capacity and crop production loss were combined to develop a composite index of vulnerability and homogenous districts were clustered into three categories, viz. low, medium and high.Wide inter-district variations were observed across the calculated indices. The result reveals that highest production losses occurred in Ganganagar district followed by Hanumangarh and Bharatpur. Pali was least exposed to the climatic variability, whereas Bundi had the maximum exposure.Jaisalmer rated the maximum sensitivity level. Further, Pratapgarh followed by Jaisalmer and Banswara had the lowest degree of adaptive capacity. On the whole, districts like Hanumangarh, Jaisalmer, Ganganagar, Bundi, Bharatpur, Jodhpur, Bikaner, Chittorgarh, Alwar, Baran and Pratapgarh exhibit high level of vulnerability to climatic change. While on the other spectrum Sirohi district was least vulnerable due to lower exposure, sensitivity, crop production loss and high adaptive capacity. The analysis, suggests the need for prioritizing vulnerable areas to arrest regional imbalances by encouraging need/ location based interventions for moderating the degree of vulnerability, whilst making agro-ecosystem in Rajasthan resilient to climatic aberrations.
\end{abstract}

Keywords : Climate Change, crop production loss, exposure, sensitivity, adaptive capacity, vulnerability

Globally, climate change poses significant risks across diverse ecosystems. In its sixth assessment report, the Intergovernmental Panel on Climate Change (IPCC, 2018) states that dryland regions and population dependent on agriculture-based livelihoods are disproportionately at a higher risk to the climate variability.The increasing frequency of inter-season variations in rainfall and temperature and other extreme events have significant impact on agriculture production and livelihoods particularly in India, where 60 per cent of the total cropped is still rainfed and large proportion of landholdings are small and fragmented (Jain et al., 2015;Udmale et al., 2014). It is increasingly recognized that variations in climate parameters is likely to exacerbate vulnerability of farming and rural communities in semi-arid tropics, which are already disadvantaged due to low and erratic precipitation pattern, lower soil fertility, higher frequency of droughts, weak institutional setup and inadequate access to resources (Bantilan and Anupama,2006, Singh et al., 2014). Adaptation actions against the adverse effects of climate induced perturbations are pertinent to sustain crop productivity and livelihood of the farmers in short to medium run (Singh et al., 2018). However, understanding the degree of vulnerability to climate change is a prelude for identification and prioritization of vulnerable areas, factors that serve as barriers to effective adaptation and for constructing suitable region-specific interventions to better cope up with current and future climate changes.

Rajasthan is the largest state in the country, spread over an area of $342,239 \mathrm{sq} . \mathrm{km}$. The topography of the state is dominated by the Aravalli hills and 70 per cent of desert in the western and north-western region, known as the Great Indian Thar Desert. Administratively, Rajasthan is segregated into 33 districts within 10 agro-climatic zones. The climate of the state vary from semi-arid to arid; with average annual temperature ranging between 0 and $50^{\circ} \mathrm{C}$. The state receives an annual average rainfall which varies from $480 \mathrm{~mm}$ to $750 \mathrm{~mm}$ and about 90 per cent of which occurs during the south west monsoon period which starts from June and last until September. Nearly 75 per cent of Rajasthan's population resides in rural areas (Census, 2011) and is predominately engaged in agriculture and livestock rearing for their livelihoods. Out of the total cropped area of 18.262 Mha in the state, 75 per cent is rainfed, which makes its agro- 
ecosystem highly susceptible to the climate induced perturbation. Generally, the state is marked by scarcity of water resources due to relatively low and erratic precipitation pattern, a sizeable portion of which reverses back because of the arid conditions, leading to lower groundwater recharge (CGWB, 2017). Recurrence of drought is a major phenomenon in the state which severely affects food grain production and livestock, leading toinsecure livelihoods and migration. A study by Rathore (2005) found that, in 48 out of 102 years (1901-2002), Rajasthan was affected by drought of varied intensity, with highest frequency observed in the western and southern regions of the state. Moreover, in the year 2016, 19 out of 33 districts in Rajasthan were affected to famine or drought conditions. Desertification resulting from shifting of sand dunes and dust storm, overgrazing and rising population has been another serious environmental issue especially in the districts of Bikaner, Churu and Nagaur located close to the desert (Kundu et al., 2015). Under future climate change, the state is likely to experience warming with annual mean temperature projected to increase by $2-2.5^{\circ} \mathrm{C}$ by 2021-2050 (Gopalakrishnan et al., 2011), while rainfall is likely to show a slight decrease (Kumar et al., 2006). These future projections of climate variability indicate greater frequency of extremes, evaporation and shortage of water,which will adversely affect crop yields and livelihood sustainability.Keeping this in view, this paper attempts to assess and quantify climate change vulnerability in semi-arid and arid regions of Rajasthan, India using multi-dimensional set of indicators.

\section{MATERIALS AND METHODS}

The study used district level data on climate and socio-economic indicators as shown in Table 1, to compute potential impact and vulnerability index,conceptualized as a combination of crop production loss, sensitivity, exposure and adaptive capacity index;

$$
\begin{aligned}
& P I_{j}=E_{j}+S_{j}+C P L_{j} \\
& V_{j}=\left(E_{j}+S_{j}+C P L_{j}\right)-A C_{j}
\end{aligned}
$$

where, $P I j$ is potential impact, $V j$ is vulnerability, $E j$ is exposure, $S j$ is sensitivity, $C P L j$ is crop production loss and $A C j$ is adaptive capacity for the $j^{\text {th }}$ district. The data on selected indicators was collected from Directorate of Economics and Statistics, Ministry of Agriculture and Farmers Welfare, Indian Meteorological Department, Census of India, and Central Ground Water Board, Ministry of Water Resources, River Development and Ganga Rejuvenation.
Kumar et al. (2016) method was adopted for estimating crop production loss, which segregates crop losses into three different effects viz., area, yield and interaction effects, as shown in equation (3). To reduce the influence of agriculture technological advancement/ long-term trend, in order to determine the net effect of climate variations, both area and yield were first de-trended using a linear model.

$$
\begin{aligned}
& C P L_{i}=\frac{1}{t_{n}}\left\{\sum_{t=1}^{n} Y_{t}\left(A_{m}-A_{t}\right)+\sum_{t=1}^{n} A_{t}\left(Y_{m}-Y_{t}\right)+\sum_{t=1}^{n}\left(A_{m}-A_{t}\right)\left(Y_{m}-Y_{t}\right)(3)\right. \\
& \mathrm{t}=1,2,3 \ldots \ldots \ldots \ldots . .20
\end{aligned}
$$

Where, $P L i$ is an average production loss for a crop in a particular district, $Y t$ and $A t$ are the actual area and yield during $\mathrm{i}^{\text {th }}$ year, respectively. A_m and Y $m$ are potential area and yield achieved during the period from 1998-2016, respectively.

Using Iyengar and Sudarshan (1982) methodology, selected indicators was normalized in the range of 0 and 1, based on their functional relationship with the component. Eq.(4) was employed for indicators positively related with the component, while eq. (5) was used for negative indicator;

$$
\begin{aligned}
& Q_{i j}=\frac{K_{i j}-\operatorname{Min}\left(X_{i j}\right)}{\operatorname{Max}\left(X_{i j}\right)-\operatorname{Min}\left(X_{i j}\right)} \\
& Q_{i j}=\frac{\operatorname{Max}\left(X_{i j}\right)-K_{i j}}{\operatorname{Max}\left(X_{i j}\right)-\operatorname{Min}\left(X_{i j k}\right)} \\
& i=1,2, \ldots \text { Iand } j=1,2, \ldots . . J
\end{aligned}
$$

Where, Q_ij is the normalized index value, Kij is the actual/ observed value, $\operatorname{Max}(\mathrm{Xij})$ and $\operatorname{Min}(\mathrm{Xij})$ is the maximum and minimum value of $\mathrm{i}^{\text {th }}$ indicator for the $\mathrm{j}^{\text {th }}$ district. Further the weight assigned to each indicator was determined as follows;

$$
\left[\mathrm{W}_{\mathrm{i}}=\frac{C}{\sqrt{\operatorname{Var}\left(Q_{i j}\right)}}\right](6) \text { Where, }\left\langle\mathrm{C}=\frac{1}{\left\{\sum_{i=1}^{n} \frac{1}{\sqrt{\operatorname{Var}\left(Q_{i j}\right)}}\right\}}\right\}
$$

where, $\mathrm{W}$ i denotes the weight, and $\mathrm{C}$ is a normalizing constant. The estimated weights were multiplied with the normalized indicators and aggregated to construct index $\mathrm{Z} \_\mathrm{j}$ for the $\mathrm{j}^{\text {th }}$ district; as given in equation (8)

$$
Z_{j}=\frac{\sum_{i=1}^{I} Q_{i j} * W_{i}}{\sum_{i=1}^{I} w_{i}}
$$

where, $0<\mathrm{W} \mathrm{i}<1$ and $\sum_{i=1}^{I} w_{i}=1$

Based on the index scores, homogenous districts 


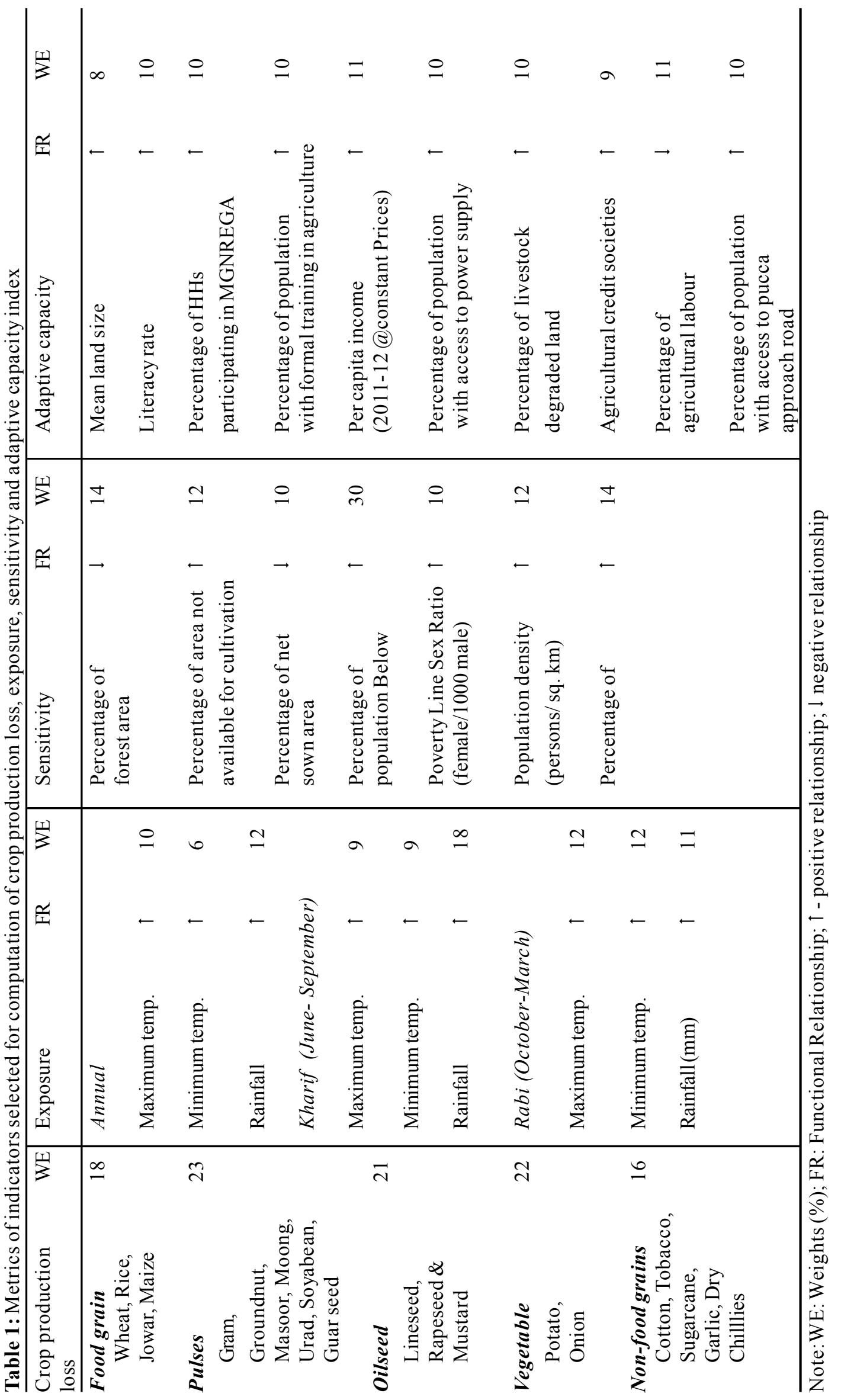




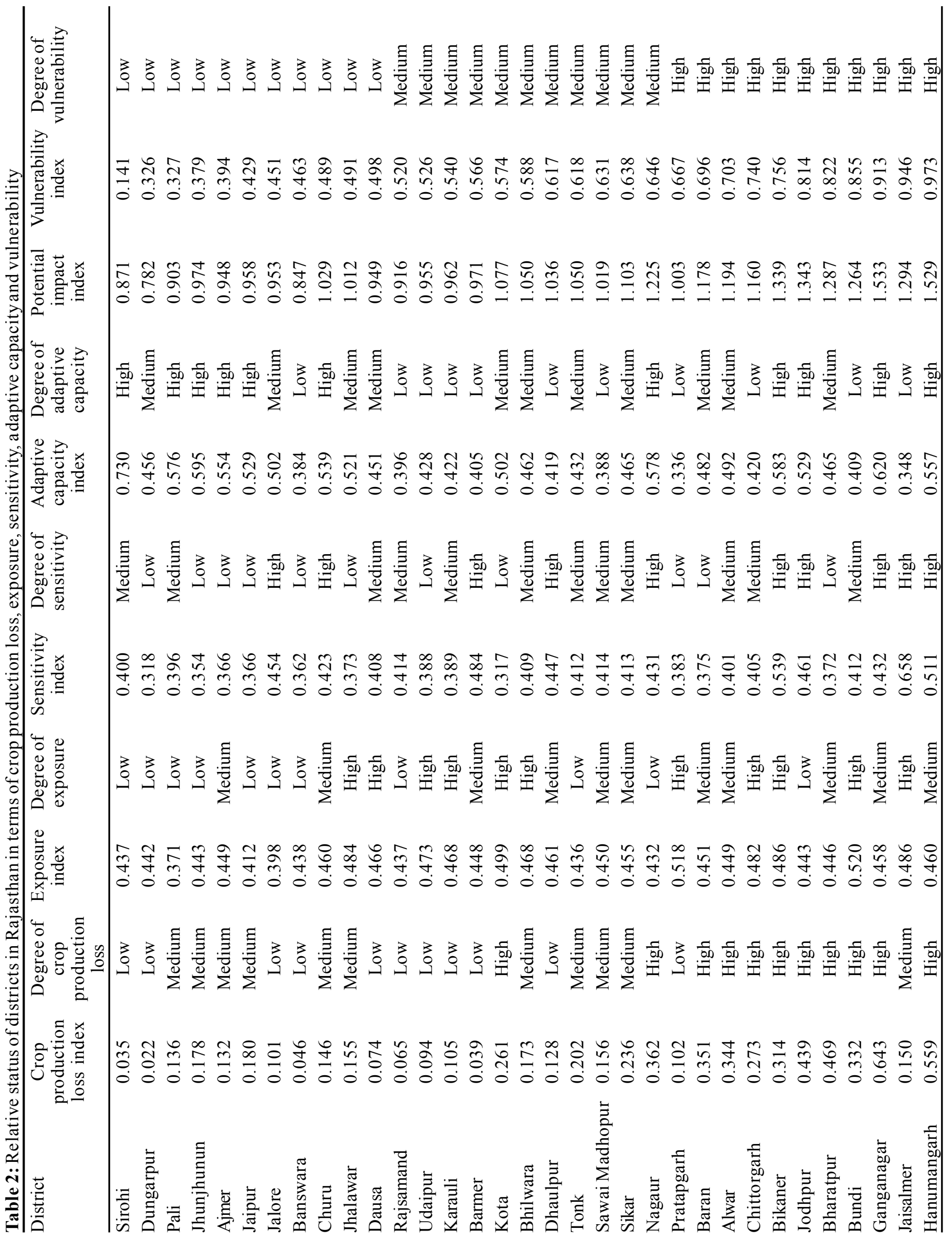


were clustered into 3 different categories; Low, Medium and High, using quartile estimation.

\section{RESULTS AND DISCUSSION}

Tables 2 depicts district-wise scores and degree of crop production loss, exposure, sensitivity, adaptive capacity and vulnerability, respectively.

\section{Crop production loss index}

During the period from 1998-2016 wide variation was observed in terms of crop loss index scores,ranging from the lowest score of 0.022 in Dungarpur to highest of 0.643 in Ganganagar. Eleven districts namely Dungarpur, Sirohi, Barmer, Banswara, Rajasmand, Dausa, Udaipur, Jalore, Pratapgarh, Karauli and Dhaulpur districts reported the lowest degree of crop production losses. While Ganganagar followed by Hanumangarh and Bharatpur occupied the top positions under the high crop loss zone, indicating relatively greater variation in production of food grains, non-food grains, oilseeds and vegetables crops.

\section{Exposure index}

Based on the calculated exposure scores during 19742015 , it was found that Pali district $(0.371)$ was least exposed to the climate variability, whereas Bundi $(0.520)$ had the maximum exposure. Slower increase in both the maximum and minimum temperature in the kharif season and annual minimum temperature were the major determinants resulting in lower degree of exposure in the Pali, Jalore, Jaipur, Nagaur, Tonk, Rajsamand, Sirohi, Banswara, Dungarpur, Jhunjhunun and Jodhpur districts. On the other spectrum, due to increase in maximum and minimum temperatures in rabi season and higher rainfall during the kharif season, Dausa, Bhilwara, Karauli, Udaipur, Chittorgarh, Jhalawar, Bikaner, Jaisalmer, Kota, Pratapgarh and Bundi districts were placed under high degree of exposure.

\section{Sensitivity index}

Kota district with score of 0.317 was least sensitive on account of lesser degraded land, lower non-cultivable area and poverty levels. On the other hand districts like Jaisalmer, Bikaner, Hanumangarh, Barmer, Jodhpur, Jalore, Dhaulpur, Ganaganagar, Nagaur and Churu were highly sensitive to climatic aberrations. Among 33 districts, 12 districts had medium level of vulnerability.

\section{Adaptive capacity index}

Inter-district variations were observed in case of adaptive capacity. Pratapgarh with the score of 0.336 followed by Jaisalmer (0.348) and Banswara (0.384) had the least adaptive capacity to deal with weather variability resulting from small number households with formal training in agriculture, poor electricity connectivity, lowermean land size and livestock population. Sirohi district $(0.730)$ had the highest capacity to cope against climatic aberrations. Factors like assured power supply, higher number of livestock, and greater participation in the MGNREGA resulted in a higher degree of adaptive capacity in the districts like, Sirohi, Ganganagar Jhunjhunu, Bikaner, Nagaur, Pali, Hanumangarh, Ajmer, Churu, Jodhpur and Jaipur.

\section{Potential impact and vulnerability index}

In terms of relative potential impact,Dungarpur district (0.782) was least impacted to climate change, whereas Ganganagar district (1.533) had the highest potential impact. Subtracting adaptive capacity from potential impact determines the vulnerability of the particular district. Sirohi district was least vulnerable, whereas Hanumangarh was most vulnerable to climate variability. In addition to Hanumangarh (0.973), Jaisalmer (0.946), Ganganagar (0.913), Bundi (0.855) and Bharatpur (0.822) were grouped as districts with high degree of vulnerability to climate change.On the other hand, on account of lower crop production losses, lesser sensitivity and higher degree of adaptive capacity Sirohi(0.141), Dungarpur (0.326). Pali, (0.327), Jhunjhunun (0.379), Ajmer (0.394), Jaipur (0.429), Jalore(0.451), Banswara (0.463), Churu (0.489) Jhalawar (0.491) and Dausa (0.498) reported lowest level vulnerability.

\section{CONCLUSIONS}

Climate change poses a serious threat to the food and livelihood security in the dry land regions and Rajasthan possessing large tract of land under arid environment, lower forest coverage and expanding desertification is at a greater risks. For formulating locally-tailored practices and policies that aims at enhancing resiliency to the weather variations, it is crucial to quantify the vulnerability status of the districts in the state. The present study found 11 out of 33 districts were highly vulnerable to the changing climatic conditions with Hanumangarh, Jaisalmer and Ganganagar having the highest degree of vulnerability. Lowest adaptive capacity was found in district like Pratapgarh, Jaisalmer, Banswara,Sawai, Madhopur, Rajsamand, Barmer, Bundi, Dholpur, Chittorgarh, Karauli and Udaipur reflecting the urgent need to strengthen the coping capacity in the districts by addressing in-situ barriers such as lack of power supply and long outages, infrastructure deficits and lack of 
opportunities (non-farm) to diversifylivelihoods. Moreover, focus on grass-root demonstration and dissemination of climate-smart technologies, drought/heat tolerant crop varieties along with integrated water resource management approaches is crucial for minimizing production losses in Hanumangarh, Bharatpur and other districts in Rajasthan. Lastly, mainstreaming climate cognitions and adaptations in the current programmes and schemes of the state is important for sustainable growth in the future.

\section{REFERENCES}

Bantilan, M.C.S. and Aupama, K.V. (2006). Vulnerability and adaptation in dryland agriculture in India's SAT: Experiences from ICRISAT's village-level studies. J. SAT Agri Res., 2(1): 1-14.

Central Ground Water Board (CGWB) (2017). Ground Water Year Book 2016-2017 Rajasthan State. Ministry of Water Resources, River Development \& Ganga Rejuvenation, Government of India, New Delhi.

Gopalakrishnan, R., Jayaraman, M. and Ravindranath, N. H. (2011). Regional Climate Modeling results for Rajasthan state. Presented at the workshop, Science-based policyoptions for climate change adaptation in Rajasthan. 24-25 February 2011. Organized by Rajasthan state pollution control Board, Jaipur, Rajasthan.

IPCC. (2018). Summary for Policymakers. In: Global Warming of $1.5^{\circ}$ C. Masson-Delmotte, V., P. Zhai, H.-O. Pörtner, D. Roberts, J. Skea, P.R. Shukla, A. Pirani, W. MoufoumaOkia, C. Péan, R. Pidcock, S. Connors, J.B.R. Matthews, Y. Chen, X. Zhou, M.I. Gomis, E. Lonnoy, T. Maycock, M. Tignor, and T. Waterfield (Eds.)], World Meteorological Organization, Geneva, Switzerland, 32 pp.

Iyengar, N.S. and Sudarshan, P. (1982). A method of classifying regions from multivariate data. Econ. Political Wkly., 2047-2052.
Jain, M., Naeem, S., Orlove, B., Modi, V. and DeFries, R.S. (2015). Understanding the causes and consequences of differential decision-making in adaptation research: adapting to a delayed monsoon onset in Gujarat, India. Global Environ Chang., 31: 98-109.

Kumar,K.R., Sahai,A.K. Kumar, K.K., Patwardhan, S.K., Mishra, P.K., Revadekar, J.V., Kamala, K. and Pant, G.B. (2006). High-resolution climate change scenarios for India for the 21 st century. Curr. Sci., 90(3): 334-345.

Kumar, S., Raizada, A., Biswas, H., Srinivas, S. and Mondal, B. (2016).Application of indicators for identifying climate change vulnerable areas in semi-arid regions of India. Ecol. indicators., 70: 507-517.

Kundu, A., Patel, N.R., Saha, S.K. and Dutta, D. (2015). Monitoring the extent of desertification processes in western Rajasthan(India) using geo-information science. Arab J. Geosci., 8(8): 5727-5737.

Rathore, M. S. (2005). State Level Analysis ofDrought Policies and Impacts in Rajasthan, India. IWMI Working Paper 93: Drought Series Paper 6. IWMI, Colombo, Sri Lanka.

Singh, N.P., Anand, B. and Khan, M.A. (2018). Micro-level perception to climate change and adaptation issues: A prelude to mainstreaming climate adaptation into developmental landscape in India. Nat Hazards., 92(3): 1287-1304.

Singh, N.P., Bantilan, C. and Byjesh, K. (2014). Vulnerability and policy relevance to drought in the semi-arid tropics of Asia-A retrospective analysis. Weather Clim Extrem. 3: 54-61.

Udmale, P., Ichikawa, Y., Manandhar, S., Ishidaira, H. and Kiem, A.S. (2014). Farmers perception of drought impacts, local adaptation and administrative mitigation measures in Maharashtra State, India. Int. J. Disaster Risk Reduct., 10: 250-269. 